\title{
Assessment of Maxillary and Mandibular Bone Mineral Density in Controlled Type II Diabetes in Completely Edentulous Patients Using Cone-Beam Computed Tomography-A Cross Sectional Study with Comparison Group
}

\author{
Sushant M. Patil1* ${ }^{*}$, Arun N. Khalikar1, Suryakant C. Deogade1, \\ Amit R. Parate ${ }^{2}$, Snehal Bansod ${ }^{3}$, Dinesh Naitam4 \\ ${ }^{1}$ Department of Prosthodontics and Crown and Bridge, Government Dental College and Hospital, Nagpur, Maharashtra, India \\ ${ }^{2}$ Department of Oral Diagnosis, Medicine and Maxillofacial Radiology, Government Dental College and Hospital, Aurangabad, \\ Maharashtra, India \\ ${ }^{3}$ Department of Oral and Maxillofacial Surgery, Matri Dental College and Research Centre, Anjora, Durg, Chhattisgarh, India \\ ${ }^{4}$ Department of Dentistry, Government Medical College and Hospital, Akola, Maharashtra, India \\ Email: ^sush9s@rediffmail,com,drkhalikar@yahoo.com,dr_deogade@yahoo.com,amit_parate11@rediffmail.com, \\ drsnehalbansod@gmail.com, dinesh_naitam@rediffmail.com
}

How to cite this paper: Patil, S.M., Khalikar, A.N., Deogade, S.C., Parate, A.R., Bansod, S. and Naitam, D. (2021) Assessment of Maxillary and Mandibular Bone Mineral Density in Controlled Type II Diabetes in Completely Edentulous $\mathrm{Pa}$ tients Using Cone-Beam Computed Tomography-A Cross Sectional Study with Comparison Group. Open Journal of Stomatology, 11, 422-436.

https://doi.org/10.4236/ojst.2021.1110037

Received: September 14, 2021

Accepted: October 24, 2021

Published: October 27, 2021

Copyright $\odot 2021$ by author(s) and Scientific Research Publishing Inc. This work is licensed under the Creative Commons Attribution International License (CC BY 4.0).

http://creativecommons.org/licenses/by/4.0/

\begin{abstract}
This study was undertaken to assess and compare bone mineral density in nondiabetic and controlled diabetic subjects using cone beam computed tomography. A group of 60 completely edentulous patients, comprising of 30 nondiabetic and 30 controlled type 2 diabetics between the age group of 45 75 years, were enrolled in the study. Glycemic control of the diabetics was assessed using glycosylated hemoglobin test and level between $6.1 \%-8 \%$ was considered controlled. A radiographic stent was fabricated for each patient by using chemically cured transparent acrylic resin. Bone densities at trabecular, buccal and lingual cortical regions of maxillary and mandibular ridges were measured by a cone beam tomography machine in Hounsfield units. The data thus obtained at 10 prospective oral implant sites of maxillary and mandibular ridges were tabulated and analyzed using STATA, version 14.0 statistical software. This study results showed no significant changes in the bone mineral density between the nondiabetic and controlled diabetic subjects. Within the limitations of this study, it can be concluded that bone mineral density does not seem to be affected in controlled type 2 diabetic patients.
\end{abstract}

\section{Keywords}

Diabetes, Bone Density, Tomography, Dental Implants 


\section{Introduction}

Osseointegrated endosseous oral implants provide a predictable, effective and reliable means for replacement of missing natural dentition in partially and completely edentulous patients. Advancement in biomaterials, implant science, nanotechnology, improved biotechnology, surgical technique, and an understanding of bone implant interface has resulted in improved outcomes and an expanded utilization of oral implants. However, outcomes can also be adversely influenced by factors like inadequate bone quantity and quality, underlying systemic diseases and metabolic disorders [1]. In 2015, the International Diabetes Federation (IDF) estimated 415 million adults with diabetes worldwide, and the number will increase to 642 million by 2040. In type 2 diabetes mellitus (T2DM) there is progressive loss of adequate beta cell insulin secretion, frequently on background of insulin resistance while in type 1 diabetes mellitus (T1DM) there is autoimmune beta cell destruction, usually leading to absolute insulin deficiency, including latent autoimmune diabetes in adulthood [2]. Both types interfere in bone formation, impair healing, induce hyperglycemia and increased advanced glycation end products (AGE) formation, reactive oxygen species (ROS) generation and inflammation. These factors lead to the increased osteoclast population and reduced osteoblast count and bone formation [3]. However recently diabetes has also been shown to be associated with decreased bone mineral density (BMD), osteopenia or osteoporosis, and impaired bone regeneration potentials [4] [5]. As life expectancy continues to increase, an implantologist can expect an increased number of patients in need of oral implant in relative contraindicated metabolic disorders like, diabetes mellitus [1].

The quantification of BMD for such patients therefore, becomes imperative. Bone density is the amount of mineral matter per square centimeter of bone and witnesses several classifications and procedures for the determination of maxillary and mandibular jaw bone density [6]. Dual energy X-ray absorptiometry (DEXA) is considered "gold standard" for measurement of BMD. In the study conducted by Lobna Metal, for assessment of mandibular BMD, using DEXA and cone beam computed tomography (CBCT) in type 2 diabetes mellitus patients; they concluded СBCT plays an important role in identifying patients with low BMD [7]. A comparative study of BMD in male and female of various age groups, conducted by Sawal A et al., shows non-significant association between male and female genders in BMD evaluation [8]. Recently, $\mathrm{CBCT}$ has been routinely used as preoperative tool for implant treatment planning to evaluate both, volume and BMD from single scan [7] [9]. CBCT is considered superior because of its high definition, reduction of the exposure dose, low cost, and usability comparable with conventional medical computed tomography (CT) [10]. Hence, the purpose of this study was to assess the bone mineral density in controlled diabetic and nondiabetic edentulous patients using $\mathrm{CBCT}$. 


\section{Materials and Method}

\subsection{Sample Size Estimation}

Base on the results of study performed by Jolly et al. with the mean and standard deviation (SD) provided, sample size was calculated using Epi info, sample size calculation software using following parameters.

$$
n=\frac{2(Z \text { alpha }+Z \text { beta })^{2} S^{2}}{d^{2}}
$$

alpha error $-5 \%$, beta error-20\%;

$m_{1}=$ mean maxillary lingual BMD in nondiabetic patients = 636.58;

$m_{2}=$ mean maxillary lingual BMD in controlled diabetic patients $=590.75$.

$$
S=\frac{S_{1}^{2}+S_{2}^{2}}{2}
$$

$S_{1}=\mathrm{SD}$ of mean $=43.41$

$S_{2}=\mathrm{SD}$ of mean $=73.24$.

Sample size was calculated to be 28 per group. This was closely rounded to 30 per group.

\subsection{Methodology}

A group of sixty completely edentulous patients, comprising of 30 nondiabetic and 30 controlled diabetic were included in study through convenience sampling based out of hospital records. The age of participant was in the range of 45 - 75 years. All the subjects were informed about the study and written consent was obtained from each of them. The required permissions were obtained from institutional ethical committee before beginning with study. The subjects were enrolled on the basis of certain inclusion and exclusion criteria. The nondiabetic subjects without any systemic disease or endocrine or metabolic or skeletal bone disorders that might affect bone mineral density were included in the present study. Similarly, subjects with controlled diabetes having glycosylated hemoglobin (HbA1c) levels within the range $6.1 \%-8 \%$ and with history of T2DM in the past 3 years were included. Subjects with elevated post meal sugar level were excluded from the study. The routine investigations such as panoramic radiographs, blood and urine analysis etc., were performed to rule out any intra-alveolar pathologies, systemic, endocrine, metabolic, or skeletal bone disorders. Diagnostic impression of both the edentulous arches was made with irreversible hydrocolloid impression material (Algitex, DPI) and (MAARC, Yellow stone plaster) was poured. Ten prospective implant sites corresponding to the location of central incisor, lateral incisor, canine, premolar, and molar were marked on either side of both the arches using a graphite pencil $(0.5 \mathrm{~mm}$ APSARA Platinum). After this, gutta-percha (GP) cones (1 mm diameter $\times 1$ $\mathrm{mm}$ height) were fixed with cyanoacrylate adhesive at the corresponding 10 sites on the cast of each arch (Figure 1(a) \& Figure 1(b)). On this, a radiographic stent was fabricated using chemically cured transparent resin (DPI). Occlusal 
rims were prepared on these stents and adjusted for proper vertical and horizontal intermaxilllary relation and were sealed in order to prevent movement of jaw during computed tomography scanning procedure (Figure 2). PLANMECA PROMAX 3D (Finland) CBCT machine with ROMEXIS software was used in this study. Patient position, radiation exposure parameter and all the other

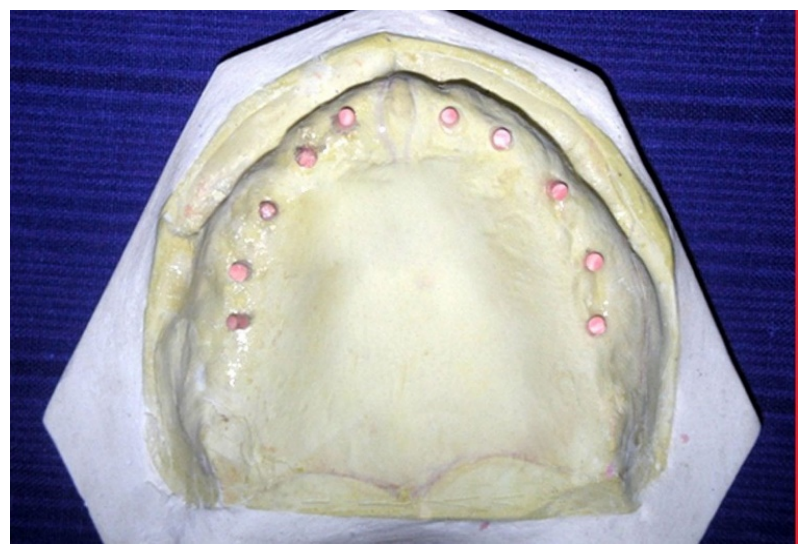

(a)

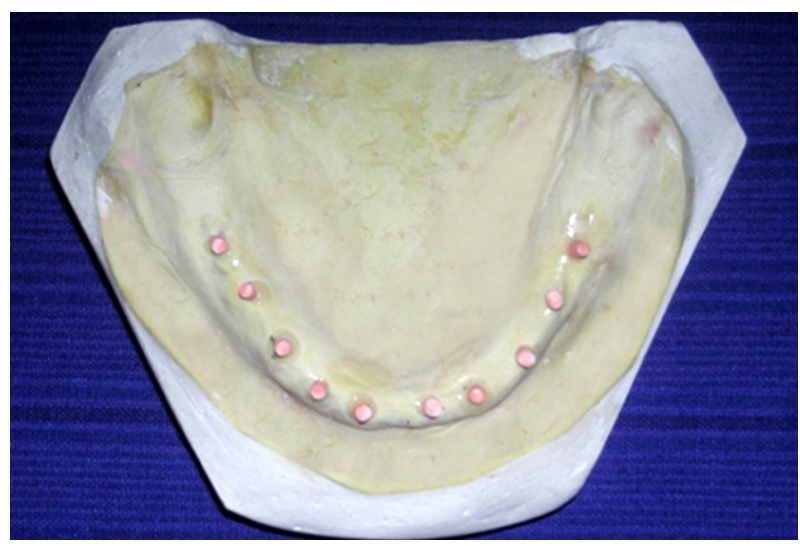

(b)

Figure 1. Gutta-percha cones fixed on (a) maxillary and (b) mandibular casts at ten prospective implants sites.

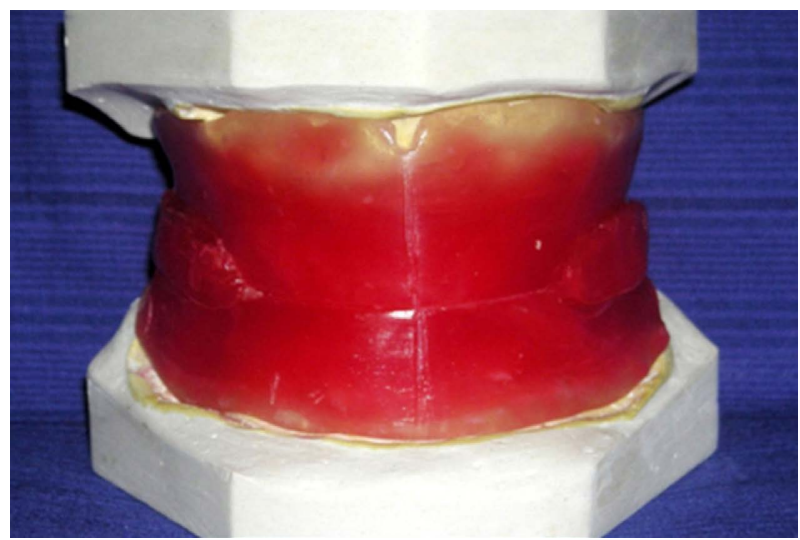

Figure 2. Radiographic stent with occlusal rims adjusted for proper intermaxillary relation to prevent jaw movements during scanning procedure. 
standard were maintained as per instruction manual and CBCT scans were obtained from enrolled subjects wearing radiographic stents. Correct position of GP markers were checked in CBCT 3D frontal and lateral images of skull (Figure 3(a) \& Figure 3(b)). The reformatted images of CBCT data result in three basic image types (axial, sagittal and coronal) with a computer-generated superimposed cure of the alveolar process and the associated reformatted alveolar cross-sectional and panoramic images (Figure 4(a) \& Figure 4(b)). Panoramic images of both the jaws were made after which images from virtual implant placement option at each prospective implant site were evaluated for BMD in Hounsfield Unit (HU). The BMD in the various sites i.e., trabecular and cortical were assessed by locating a cursor at the different position on the image and were expressed in the $\mathrm{HU}$. The BMD values were recorded on the slices in the trabecular and cortical regions of both the jaws, and the mean values were calculated. The data thus obtained was tabulated and statistically analyzed using, two sample $t$ test and paired t test in STATA, version 14.0 statistical software. The descriptive statistics was entered and expressed in terms of mean \pm SD (standard deviations) of BMD in various prospective sites.

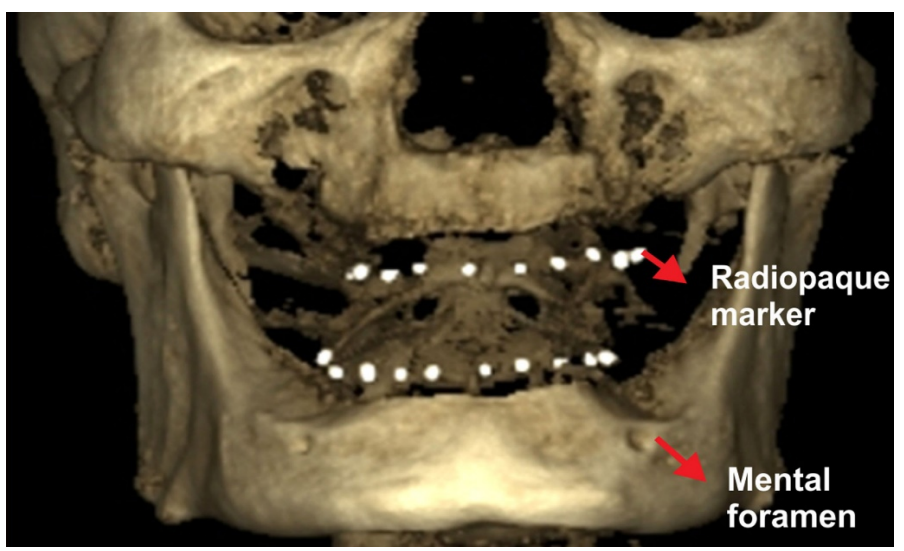

(a)

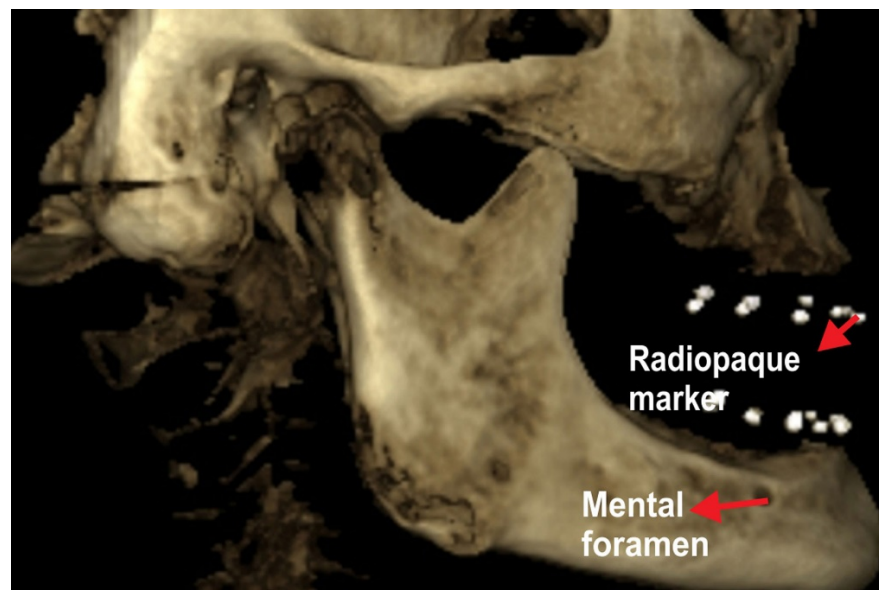

(b)

Figure 3. Correct position of gutta-percha markers checked in CBCT, 3D (a) frontal and (b) lateral images of skull. 


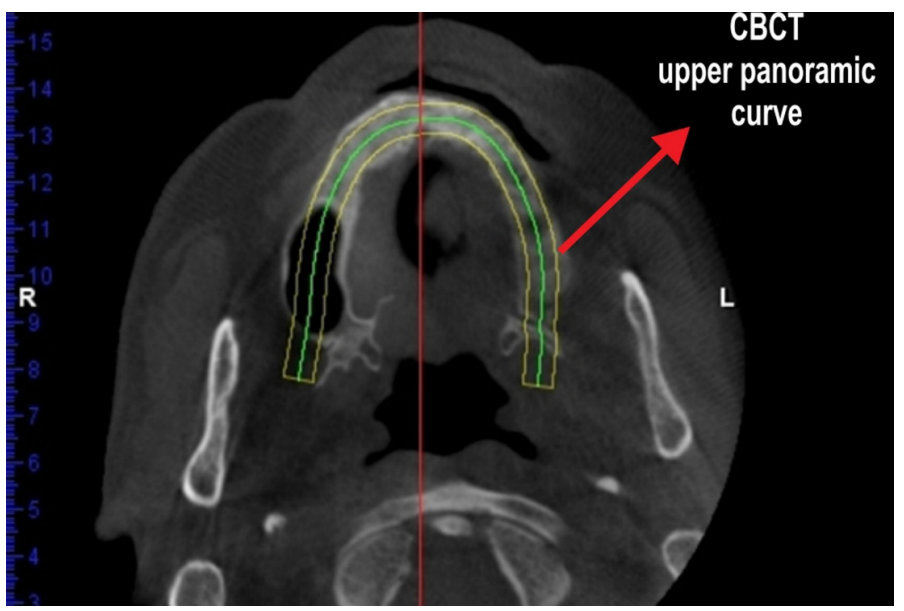

(a)

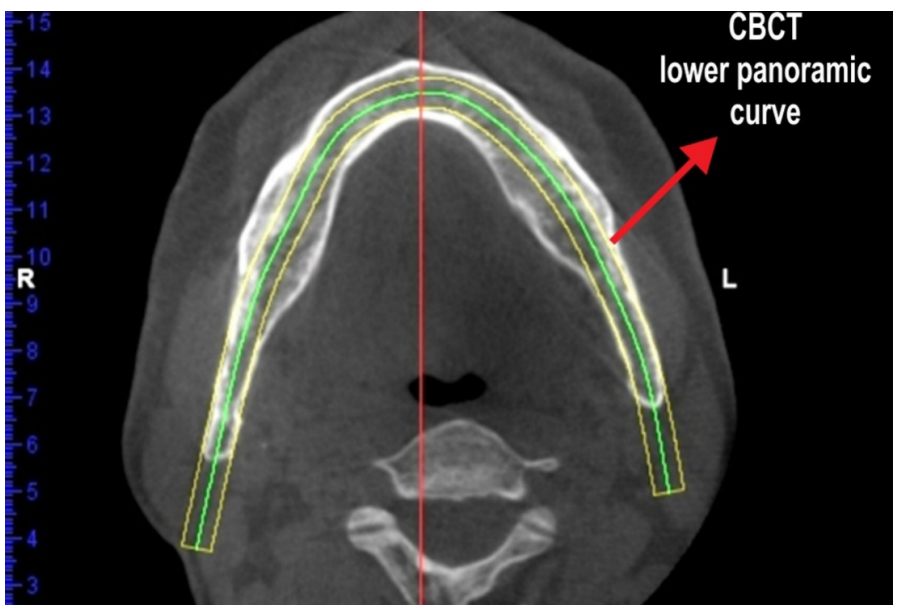

(b)

Figure 4. Computer generated super-imposed curve in (a) maxillary and (b) mandibular images of skull.

\section{Result}

Collected data was entered into Microsoft Excel spreadsheet. Tables and charts were generated using Microsoft Word and Microsoft Excel software. Continuous variables were presented as Mean \pm SD and also 95\% confidence interval. On analyzing the results in (Table 1), Mean trabecular BMD in maxilla of nondiabetic was $247.7496 \pm 114.1547 \mathrm{HU}$, whereas in controlled diabetics it was $230.8417 \pm 83.97667 \mathrm{HU}$. Diabetics showed slightly less BMD when compared to nondiabetics and similarly, mean trabecular BMD in mandible of nondiabetics was $421.7454 \pm 178.8523 \mathrm{HU}$, whereas in controlled diabetics it was $380.2802 \pm$ $159.0474 \mathrm{HU}$.

\section{Statistical Analysis}

Mean BMD among trabecular, buccal, lingual of maxilla and mandible in non-diabetic and controlled diabetic patients were compared by performing one-way ANOVA (Table 2). Post hoc comparison was made by performing 
Table 1. Comparison of bone mineral density at trabecular, buccal cortical and lingual cortical regions of maxilla and mandible in nondiabetic and controlled diabetic subjects in Hounsfield unit (HU).

\begin{tabular}{|c|c|c|c|c|c|c|c|}
\hline Region & Group & Class & Mean & $\begin{array}{c}\text { Std. } \\
\text { Deviation }\end{array}$ & $\begin{array}{l}\text { Degree of } \\
\text { freedom }\end{array}$ & $\begin{array}{l}95 \% \text { confidence } \\
\text { interval }\end{array}$ & $\begin{array}{l}\text { Unpaired } \\
t \text { test }\end{array}$ \\
\hline \multirow{4}{*}{$\begin{array}{l}\text { Trabe } \\
\text {-cular }\end{array}$} & \multirow{2}{*}{ Maxilla } & Nondiabetic & 247.74 & 114.15 & \multirow[t]{2}{*}{58} & $205.12-290.38$ & \multirow{2}{*}{$\begin{array}{c}\mathrm{p}=0.5160 \\
\mathrm{NS}\end{array}$} \\
\hline & & Controlled diabetic & 230.84 & 83.97 & & $199.48-262.20$ & \\
\hline & \multirow{2}{*}{ Mandible } & Nondiabetic & 421.74 & 178.85 & \multirow[t]{2}{*}{58} & $354.96-488.53$ & \multirow{2}{*}{$\begin{array}{c}\mathrm{p}=0.3466 \\
\mathrm{NS}\end{array}$} \\
\hline & & Controlled diabetic & 380.28 & 159.04 & & $320.89-439.67$ & \\
\hline \multirow{4}{*}{$\begin{array}{l}\text { Buccal } \\
\text { cortical }\end{array}$} & \multirow{2}{*}{ Maxilla } & Nondiabetic & 462.31 & 133.53 & \multirow[t]{2}{*}{58} & $412.45-512.18$ & \multirow{2}{*}{$\begin{array}{c}\mathrm{p}=0.9490 \\
\mathrm{NS}\end{array}$} \\
\hline & & Controlled diabetic & 460.33 & 103.03 & & $421.86-498.81$ & \\
\hline & \multirow{2}{*}{ Mandible } & Nondiabetic & 1056.85 & 174.46 & \multirow[t]{2}{*}{58} & $991.71-1122$ & \multirow{2}{*}{$\begin{array}{c}\mathrm{p}=0.6252 \\
\text { NS }\end{array}$} \\
\hline & & Controlled diabetic & 1077.63 & 152.54 & & $1020.7-1134.6$ & \\
\hline \multirow{4}{*}{$\begin{array}{l}\text { Lingual } \\
\text { cortical }\end{array}$} & \multirow{2}{*}{ Maxilla } & Nondiabetic & 374.55 & 96.07 & \multirow[t]{2}{*}{58} & $338.68-410.43$ & \multirow{2}{*}{$\begin{array}{c}\mathrm{p}=0.4637 \\
\mathrm{NS}\end{array}$} \\
\hline & & Controlled diabetic & 392.55 & 92.93 & & $357.85-427.25$ & \\
\hline & \multirow{2}{*}{ Mandible } & Nondiabetic & 870.25 & 142.26 & \multirow[t]{2}{*}{58} & $817.13-923.38$ & \multirow{2}{*}{$\begin{array}{c}\mathrm{p}=0.6667 \\
\mathrm{NS}\end{array}$} \\
\hline & & Controlled diabetic & 885.04 & 121.54 & & $839.66-930.43$ & \\
\hline
\end{tabular}

NS (Non-Significant).

Table 2. One-way ANOVA comparison of mean bone mineral density amongst, trabecular, buccal cortical and lingual cortical regions of maxilla and mandible in nondiabetic and controlled diabetic subjects in Hounsfield Units (HU).

\begin{tabular}{|c|c|c|c|c|c|c|}
\hline Class & Group & Region & Mean & $\begin{array}{l}\text { Standard } \\
\text { Deviation }\end{array}$ & $\begin{array}{l}95 \% \text { confidence } \\
\text { interval }\end{array}$ & $\begin{array}{c}\text { Oneway ANOVA } \\
\text { test }\end{array}$ \\
\hline \multirow{6}{*}{ Non diabetic } & \multirow{3}{*}{ Maxilla } & Trabecular & 247.74 & 114.15 & $119.28-479.24$ & \multirow{3}{*}{$\begin{array}{c}F=26.12, \\
p<0.0001, H S\end{array}$} \\
\hline & & Buccal cortical & 462.31 & 133.53 & $280.82-707.21$ & \\
\hline & & Lingual cortical & 374.55 & 96.07 & $247.25-545.97$ & \\
\hline & \multirow{3}{*}{ Mandible } & Trabecular & 421.74 & 178.85 & $156.20-754.91$ & \multirow{3}{*}{$\begin{array}{c}F=116.01, \\
p<0.0001, H S\end{array}$} \\
\hline & & Buccal cortical & 1056.85 & 174.46 & $831.85-1272.79$ & \\
\hline & & Lingual cortical & 870.25 & 142.26 & $635.33-1156.96$ & \\
\hline \multirow{6}{*}{$\begin{array}{l}\text { Controlled } \\
\text { diabetic }\end{array}$} & \multirow{3}{*}{ Maxilla } & Trabecular & 230.84 & 83.97 & $107.99-393.77$ & \multirow{3}{*}{$\begin{array}{c}\mathrm{F}=47.57, \\
\mathrm{p}<0.0001, \mathrm{HS}\end{array}$} \\
\hline & & Buccal cortical & 460.33 & 103.03 & $286.62-600.99$ & \\
\hline & & Lingual cortical & 392.55 & 92.93 & $208.67-549.49$ & \\
\hline & \multirow{3}{*}{ Mandible } & Trabecular & 380.28 & 159.04 & $194.08-793.53$ & \multirow{3}{*}{$\begin{array}{c}F=184.29 \\
p<0.0001, H S\end{array}$} \\
\hline & & Buccal cortical & 1077.63 & 152.54 & $882.73-1337.92$ & \\
\hline & & Lingual cortical & 885.04 & 121.54 & $692.44-1024.69$ & \\
\hline
\end{tabular}

HS (Highly significant).

Bonferroni t-test as multiple comparison test (Table 3). Mean BMD at different region was compared between nondiabetic and controlled diabetic by performing independent $\mathrm{t}$-test for maxilla and mandible and also between maxilla and mandible in non-diabetic and controlled diabetic group. $\mathrm{p}<0.05$ was considered 
Table 3. Multiple comparison of bone mineral density by Bonferroni t-test amongst, trabecular, buccal cortical and lingual cortical regions of maxilla and mandible in nondiabetic and controlled diabetic subjects in Hounsfield Units (HU).

\begin{tabular}{|c|c|c|c|c|}
\hline Class & Group & Regions & Mean difference & p-value \\
\hline \multirow{6}{*}{$\begin{array}{c}\text { Non } \\
\text { diabetic }\end{array}$} & \multirow{3}{*}{ Maxilla } & Trabecular - Buccal cortical & 214.56 & $\mathrm{p}<0.0001, \mathrm{HS}$ \\
\hline & & Trabecular - Lingual cortical & 126.80 & $\mathrm{p}<0.0001, \mathrm{HS}$ \\
\hline & & Buccal cortical - Lingual cortical & -87.76 & $\mathrm{p}=0.013, \mathrm{~S}$ \\
\hline & \multirow{3}{*}{ Mandible } & Trabecular - Buccal cortical & 635.11 & $\mathrm{p}<0.0001, \mathrm{HS}$ \\
\hline & & Trabecular - Lingual cortical & 448.59 & $\mathrm{p}<0.0001, \mathrm{HS}$ \\
\hline & & Buccal cortical - Lingual cortical & -186.59 & $\mathrm{p}<0.0001, \mathrm{HS}$ \\
\hline \multirow{6}{*}{$\begin{array}{c}\text { Controlled } \\
\text { diabetic }\end{array}$} & \multirow{3}{*}{ Maxilla } & Trabecular - Buccal cortical & 229.49 & $\mathrm{p}<0.0001, \mathrm{HS}$ \\
\hline & & Trabecular - Lingual cortical & 161.71 & $\mathrm{p}<0.0001, \mathrm{HS}$ \\
\hline & & Buccal cortical - Lingual cortical & -67.78 & $\mathrm{p}=0.019, \mathrm{~S}$ \\
\hline & \multirow{3}{*}{ Mandible } & Trabecular - Buccal cortical & 697.35 & $\mathrm{p}<0.0001, \mathrm{HS}$ \\
\hline & & Trabecular - Lingual cortical & 504.76 & $\mathrm{p}<0.0001, \mathrm{HS}$ \\
\hline & & Buccal cortical - Lingual cortical & -192.59 & $\mathrm{p}<0.0001, \mathrm{HS}$ \\
\hline
\end{tabular}

HS (Highly significant), S (Significant).

as statistical significance. Statistical software STATA, version 14.0 was used for data analysis.

Diabetics showed slightly less BMD when compared to nondiabetic in trabecular bone and the variation between these two groups in maxilla and mandible were both found to be statistically nonsignificant $(\mathrm{p}=0.5160 \& \mathrm{p}=0.3466$, respectively). The buccal cortical BMD in maxilla (Figure 5) of nondiabetics was $462.317 \pm 133.5356 \mathrm{HU}$ and controlled diabetic was $460.3386 \pm 103.0346 \mathrm{HU}$. The disparity in the mean values of both the groups was statistically nonsignificant $(\mathrm{p}=0.9490)$. In mandible (Figure 6), mean buccal cortical BMD of nondiabetic was $1056.856 \pm 174.4616 \mathrm{HU}$ and of controlled diabetics was $1077.638 \pm$ $152.5496 \mathrm{HU}$. Variation in both groups was statistically nonsignificant ( $\mathrm{p}=$ 0.6252).

Mean lingual cortical BMD in maxilla and mandible was $374.5526 \pm 96.07128$ $\mathrm{HU}$ and $870.2572 \pm 142.2657 \mathrm{HU}$, respectively among nondiabetic, while it was $392.5535 \pm 92.93128 \mathrm{HU}$ and $885.0468 \pm 121.547 \mathrm{HU}$, respectively among controlled diabetic. Both the groups did not show any statistically significant difference in maxilla $(\mathrm{p}=0.4637)$ and mandible $(\mathrm{p}=0.6667)$ respectively. When we compare BMD amongst, trabecular, buccal cortical and lingual cortical region of maxilla and mandible in nondiabetic and controlled diabetic using one-way ANOVA, results are highly significant $\mathrm{p}<0.0001$. Results show BMD varies in trabecular, buccal cortical and lingual cortical region at prospective implant site. Multiple comparison by Bonferroni t-test amongst, trabecular, buccal cortical and lingual cortical region of maxilla and mandible in nondiabetic and controlled diabetic, results are highly significant $\mathrm{p}<0.0001$, in trabecular-buccal 


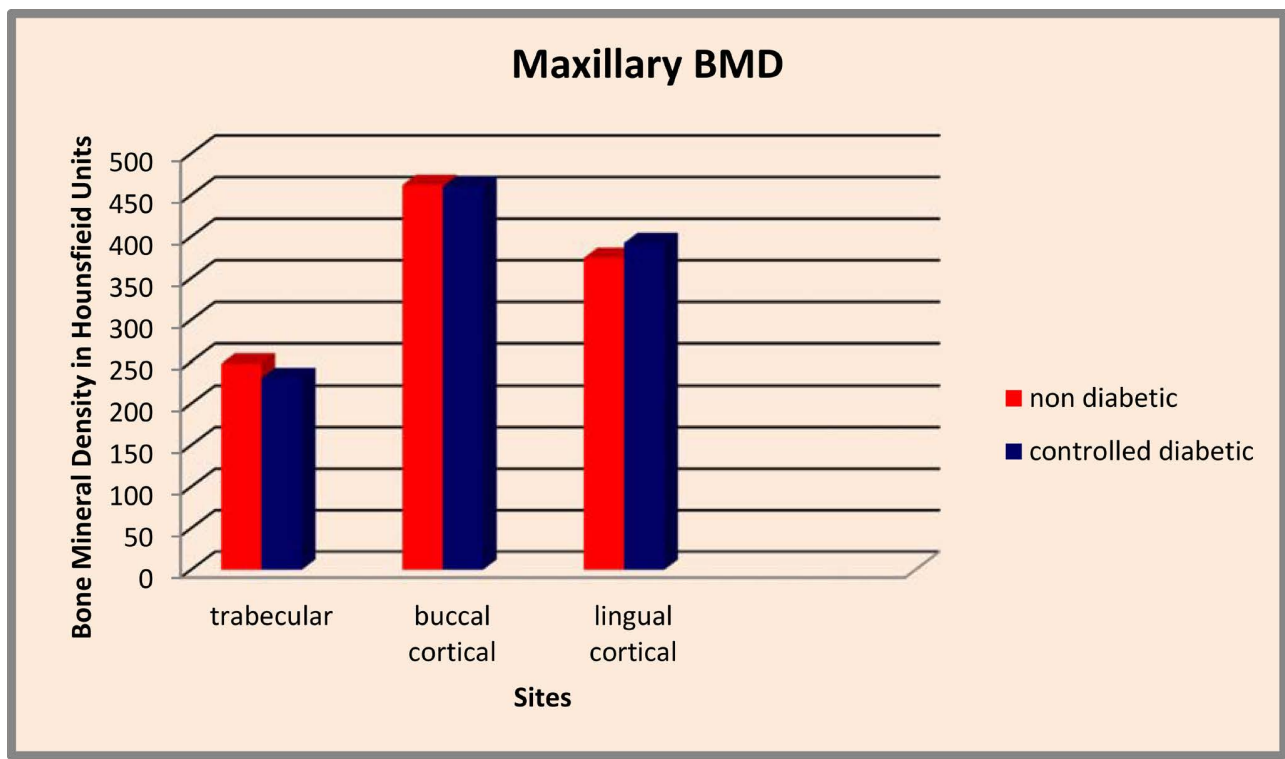

Figure 5. Graphical comparison of mineral bone density of trabecular, buccal and lingual cortical plate of maxilla in nondiabetic and controlled diabetic subjects.

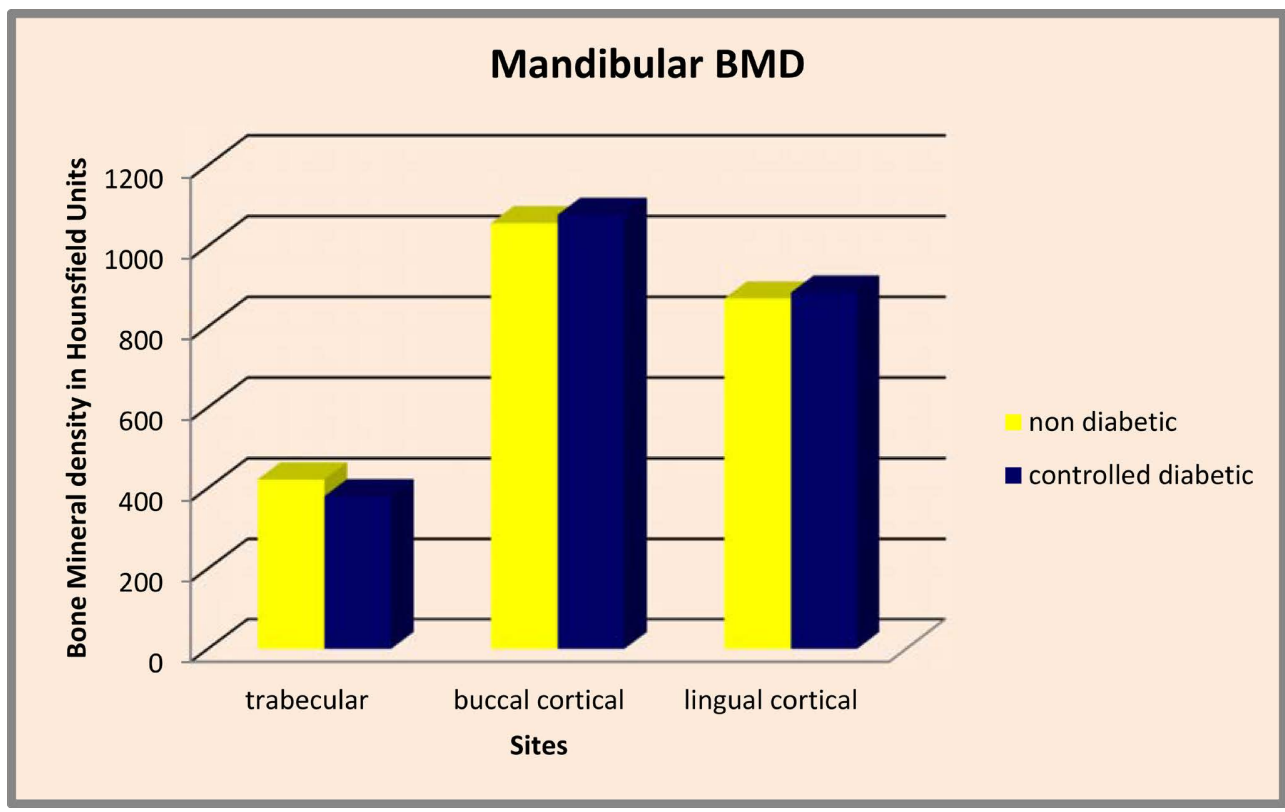

Figure 6. Graphical comparison of mineral bone density of trabecular, buccal and lingual cortical plate of mandible in nondiabetic and controlled diabetic subjects.

cortical, trabecular-lingual cortical, buccal cortical-lingual cortical, except for buccal cortical-lingual cortical in maxilla in nondiabetic and controlled diabetic where the results are significant, with $\mathrm{p}=0.013$ and $\mathrm{p}=0.019$ respectively. These results are suggestive in prescribing bucco-lingual position of implant placement as per prosthetic needs.

\section{Discussion}

The success rate of implant therapy is highly influenced by both, the quantity 
(volume) and quality (density) of available bone at the prospective site of implant placement [11]. After implant placement, the initial BMD at the recipient site provides mechanical stability during healing phase. It, also allows distribution and transmission of stresses from the prosthesis at the implant bone interface [6] [12] [13] [14] [15]. BMD at prospective implant site is a determining factor in treatment planning, implant design, surgical approach, healing time and initial progressive bone loading during prosthetic construction [16] [17]. BMD varies from site to site and from individual to individual. A $10 \%$ higher success rate of implants stability has been documented in mandible when compared with maxilla by Adell R et al. [18]. Enguist B et al. reported lower quality of bone in the maxilla when compared with mandible in a retrospective multicenter study of osseointegrated implants supporting overdentures [19]. Implant failures have been reported more in completely edentulous maxilla, in which jaw bone exhibits soft quality and sever resorption [20]. Tolstunov L, noted a significant correlation of the reduced implant survival, with bone quality and deficient vascularization at recipient sites. These findings necessitate presurgical assessment of the prospective implant site more accurately prior to implant placement [21]. Metabolic bone disease among the elderly will encounter the age-related disorder characterized by changes in bone quality, quantity and architectural configuration. India leads the world with the largest number of diabetic subjects [22]. Age related bone loss affects the jaw bones in the same manner as the other part of the skeleton that serve as diagnostic markers of the disease [23] [24]. In view of these documentations, this study was undertaken to assess and compare the $\mathrm{BMD}$ at the prospective implant sites of edentulous maxilla and mandible using CBCT in controlled diabetic and nondiabetic patients.

When compared BMD at trabecular, buccal cortical and lingual cortical bone of maxilla and mandible at prospective implant site, results did not show any statistically significant difference among nondiabetic and type 2 controlled diabetic patients (Table 1). Diabetes is characterized by hyperglycemia resulting from defects either in insulin secretion as in type 1 or in insulin action and secretion as in type 2 [2]. Glycosylated hemoglobin (HbAlc) level, which is considered as an indicator of glucose level over a three-month period, is used to assess the glycemic control in an individual. HbAlc level up to $4-6$ determines the healthy and nondiabetic status, up to $6.1-8$ determines controlled and above 8 reveals poorly controlled diabetic status. Therefore, a controlled HbA1c level may be considered as a determining factor for implant success rate [2] [25] [26]. Compare with medical CT, CBCT can be alternative method to measure BMD distribution based on X-ray attenuation coefficient of the mineral in bone tissue. It is very powerful non-destructive tool that allows for longitudinal diagnosis of patient's bone disease. Mineral density distribution of bone tissue reflects the result of biological activity, which is altered due to bone complications and in a disease like diabetes [7] [10] [27]. There is different pathogenesis in type 1 and type 2 diabetes, therefore it shows different effects on the bone, although com- 
plications like chronic hyperglycemia, hypercalciuria and negative effect of accumulated glycated end products are common in both the patients. However, the differences are in insulin concentration and insulin like-growth factors (IGF) concentration between type 1 and type 2 diabetes. This suggests increase in hepatic IGF-1 production and its increased bioavailability, may play a significant role for maintenance of bone health in type 2 diabetes [28]. This may be the contributing factors for non significant results of this study in two comparison groups.

Clinically, bone density influences the amount of trabecular, buccal and lingual bone in contact with the implant surface, not only at first stage of implant surgery, but also at the second stage and during prosthetic loading. As the bone density decreases, the strength of the bone also decreases. To reduce the incidence of microfracture in bone, stress and strain introduced to the implant should be reduced by selecting proper bucco-lingual position for placement of implant. This can also be achieved by reducing biomechanical loads on implant by scientific prosthetic design, for e.g. the cantilever length may be shortened or eliminated, narrow occlusal table designing and by minimizing off set loads. Soft tissue on residual ridges is also allowed to share the occlusal force and reduce the amount of stress on the implant as in removable prosthesis (RP) 4 and RP5 designs [29] [30]. A load directed along the long axis of the implant body decreases the amount of stress in the crestal bone at buccal and lingual cortical region compared to an angled load. As the bone density decreases, the angle of the load on the implant body should be directed more axial. Selecting a wider diameter implant in low bone density regions also decreases stress by increasing surface area of bone-implant interface [31]. When we compared, BMD at trabecular, buccal and lingual cortical bone of maxilla and mandible at prospective implant sites, in maxilla and mandible (Table 2, Table 3 ) results show statistically significant difference in both nondiabetic and controlled diabetic patients. Low BMD at trabcular region of maxilla in this study could be due to the fact that the maxilla is a stable bone, anchored to the rest of the skull, and receives load mainly from occlusal contacts carried to the alveolar and basal bone by the teeth roots. While the high value of BMD in mandible could be due to its movements, occlusal contacts and muscle actions performance, which results in proper strain conditions in its structure and thus are denser. Maxilla meanwhile, can deal with changes in dynamic and static load by virtue of the flexibility of its own bone architecture. Cancellous bone is prevalent in the maxilla because the higher degree of vascularization allows faster adaptation of the bone substratum, which consists of well organized and well-connected trabeculae that follows the force trajectories departing from the alveoli as stated by Sanfilippo et al. [32]. Buccal cortical plate of maxilla showed higher BMD than its palatal counterpart. These findings were I agree with the findings of AL-Attas MA et al. [33]. Similar findings were seen in mandibular bone where buccal cortical region showed higher BMD than lingual cortical region. This could be attributed to the fact that the muscular attachment to the bone surface by their tendon generates functional 
tensions that will strengthen bone. The muscles on the buccal side of the mandible, distal from the mental foramen, mostly provide biting force. Most muscles that are attached on the lingual side of the mandible do not produce force, but are related to more complicated movements of the tongue and mandible. The lower BMD on the lingual side may be due to weaker muscle function or due to imbalance resorption on the periosteal and, apposition of bone on the endosteal side of cortex [33] [34] [35].

Results of this study show BMD of jaw bones are not affected in patients with T2 DM, having normal glycemic levels without other relevant risk factors. Study also shows mandible has more BMD values in comparison to maxilla in trabecular, buccal and lingual cortical regions. Buccal cortical region was denser when compared with its lingual counterpart in both maxilla and mandible in both the groups.

\section{Conclusions}

The following conclusions were drawn from the ongoing study:

1) Pre-operative evaluation of $B M D$ is essential to assist the clinician with the treatment planning of intra-oral endosseous implant therapy.

2) CBCT provides both, quantitative and qualitative information of trabecular, buccal and lingual cortical bone separately, thus aiding in proper patient selection and facilitating proper assessment of potential recipient sites for implant placement.

3) BDM does not get affected in controlled T2DM patients.

4) Further studies are necessary for T1DM patients and poorly controlled T2DM patients.

\section{Conflicts of Interest}

The authors declare no conflicts of interest regarding the publication of this paper.

\section{References}

[1] Tagliaren, J.M. and Clarkson, E. (2015) Basic Concepts and Technique of Dental Implants. Dental Clinics of North America, 59, 255-264. https://doi.org/10.1016/j.cden.2014.10.005

[2] American Diabetes Association (2021) Classification and Diagnosis of Diabetes: Standards of Medical Care in Diabetes-2021. Diabetes Care, 44, S15-S33. https://doi.org/10.2337/dc21-S002

[3] Hongi, J., Xiao, E. and Graves, B.T. (2015) Diabetes and Its Effects on the Bone and Fracture Healing. Current Osteoporosis Reports, 13, 327-335. https://doi.org/10.1007/s11914-015-0286-8

[4] Paschou, S.A., Dede, A.D., Anagnostis, P.G. and Vryonidou, A. (2017) Type 2 Diabetes and Osteoporosis: A Guide to Optimal Management. The Journal of Clinical Endocrinology \& Metabolism, 102, 3621-3634. https://doi.org/10.1210/jc.2017-00042

[5] Poiana, C. and Capatina, C. (2017) Fracture Risk Assessment in Patients with Di- 
abetes Mellitus. Journal of Clinical Densitometry, 20, 432-443.

https://doi.org/10.1016/j.jocd.2017.06.011

[6] Wang, S.H., Shen, Y.W., Fuh, L.J., Peng, S.L., Tsai, M.T., Huang, H.L. and Hsu, J.T. (2020) Relationship between Cortical Bone Thickness and Cancellous Bone Density at Dental Implant Sites in the Jaw Bone. Diagnostics (Basel), 10, 710-720.

https://doi.org/10.3390/diagnostics10090710

[7] Lobna, M., Sandawy, F.R.A., Matrawy, K.S., Zeitoun, M.H. and Gaweesh, Y.S. (2019) Relationship of Cone Beam Computed Tomography Assessment of Mandibular Mineral Bone Density to Dual Energy X-Ray Absorptiometery in Type 2 Diabetes Mellitus Patients. Alexandria Dental Journal, 44, 87-92.

https://doi.org/10.21608/adjalexu.2019.57591

[8] Sawal, A., Singh, B. and Gajbe, U. (2019) Comparative Study of BMD in Male and Females of Various Age Groups. Internal National Journal of Scientific Research, 8 , 1-2.

[9] Abranmovith, K. and Rice, D.D. (2014) Basic Principles of Cone Beam Computed Tomography. Dental Clinics of North America, 59, 463-484.

https://doi.org/10.1016/j.cden.2014.03.002

[10] Jacobs, R., Salmon, B., Codari, M., Hassan, B. and Bornstein, M.M. (2018) Cone Beam Computed Tomography in Implant Dentistry: Recommendations for Clinical Use. BMC Oral Health, 18, 88-104. https://doi.org/10.1186/s12903-018-0523-5

[11] Goiato, M.C., Santos, D.M., Santiogo, J.F., Moreno, A. and Pellizzer, E.P. (2014) Longevity of Dental Implants in Type IV Bone: A Systematic Review. International Journal of Oral and Maxillofacial Surgery, 43, 1108-1116.

https://doi.org/10.1016/j.ijom.2014.02.016

[12] Marquezan, M., Osorio, A., Anna, E.S., Souza, M.M. and Maia, L. (2012) Does Bone Mineral Density Influences Primary Stability of Dental Implants? A Systematic Review. Clinical Oral Implants Research, 23, 767-774. https://doi.org/10.1111/j.1600-0501.2011.02228.x

[13] Chreanovie, B.R., Albrektsson, T. and Wennerberg, A. (2017) Bone Quality and Quantity and Dental Implant Failure: A Systematic Review and Meta-Analysis. The International Journal of Prosthodontics, 30, 219-237. https://doi.org/10.11607/ijp.5142

[14] Li, J., Yin, X., Huang, L., Mouraret, S., Brunski, J.B., Cordova, L., Salmon, B. and Helms, J.A. (2017) Relationships among Bone Quality, Implant Osseointegration, and Wnt Signaling. Journal of Dental Research, 96, 822-831. https://doi.org/10.1177/0022034517700131

[15] Bahuguna, R., Anand, B., Kumar, D., Aeran, H., Anand, V. and Gulati, M. (2013) Evaluation of Stress Patterns in Bone around Dental Implant for Different Abutment Angulations under Axal and Oblique Loading: A Finite Element Analysis. $\mathrm{Na}$ tional Journal of Maxillofacial Surgery, 4, 46-51. https://doi.org/10.4103/0975-5950.117882

[16] Alghamdi, H., Anand, P.S. and Anil, S. (2011) Undersized Implant Site Preparation to Enhance Primary Implant Stability in Poor Bone Density: A Prospective Clinical Study. Journal of Oral and Maxillofacial Surgery, 69, 506-512. https://doi.org/10.1016/j.joms.2011.08.007

[17] Gulsahi, A. (2011) Bone Quality Assessment for Dental Implant. In: Turkyilmaz, I., Ed., Implant Dentistry - The Most Promising Discipline of Dentistry, In Tech, New York, 437-452. https://doi.org/10.5772/16588

[18] Adell, R., Lekholm, U. and Rockler, B. (1981) A 15-Year Study of Osseointegrated 
Implants in the Treatment of the Edentulous Jaws. International Journal of Oral Surgery, 6, 387-416. https://doi.org/10.1016/S0300-9785(81)80077-4

[19] Enguist, B., Bergendal, T. and Kallus, T. (1988) A Retrospective Multicenter Evaluation of Osseointegrated Implants Supporting Overdentures. The International Journal of Oral \& Maxillofacial Implants, 3, 129-134.

[20] Maim, M.O., Jernt, T. and Stenport, V. (2018) Early Implant Failures in Edentulous Patients: A Multivariable Regression Analysis of 4615 Consecutively Treated Jaws: A Retrospective Study. Journal of Prosthodontics, 27, 803-812. https://doi.org/10.1111/jopr.12985

[21] Tolstunov, L. (2007) Implant Zones of the Jaws, Implant Location and Related Success Rate. Journal of Oral Implantology, 33, 211-220. https://doi.org/10.1563/1548-1336(2007)33[211:IZOT]I]2.0.CO;2

[22] Anjana, R.A., Deepa, M., Pradeeppa, R., Mahanta, J., Narain, K., Das, H.K., Adhikari, R., Paturi, V., Roa, P.V., Saboo, B. and Kumar, A. (2017) Prevalence of Diabetes and Prediabetes in 15 States of India: Results from the ICMR-INDIAB Population-Based Cross-Sectional Study. The Lancet Diabetes \& Endocrinology, 5, 585-596. https://doi.org/10.1016/S2213-8587(17)30174-2

[23] Boskey, A.L. and Imbert, L. (2017) Bone Quality Changes Associated with Aging and Disease: A Review. Annals of the New York Academy of Sciences, 1410, 93-106. https://doi.org/10.1111/nyas.13572

[24] Calciolari, E., Donos, N., Park, J.C., Petrie, A. and Madras, N. (2016) A Systematic Review on the Correlation between Skeletol and Jaw Bone Mineral Density in Osteoporotic Subjects. Clinical Oral Implants Research, 27, 433-442. https://doi.org/10.1111/clr.12597

[25] Lui, J., Ludwig, T. and Ebraheim, N.A. (2013) Effect of the Blood HbA1c Level on Surgical Treatment Outcomes of Diabetics with Ankle Fractures. Orthopaedic Surgery, 5, 203-208. https://doi.org/10.1111/os.12047

[26] Wang, J., Luo, X., Meng, L.V., Dou, J., Zeng, J., An, P., Chen, Y., Chen, K. and Mu, Y. (2020) Effect of Preoperative HbA1c Levels on the Postoperative Outcomes of Coronary Artery Disease Surgical Treatment in Patiect with Diabetes Mellitus and Non Diabetic Patients: A Systematic Review and Meta-Analysis. Journal of Diabetes Research, 1-14. https://doi.org/10.1155/2020/3547491

[27] Kim, D.G. (2014) Can Dental Cone Beam Computed Tomography Assess Bone Mineral Density? Journal of Bone Metabolism, 21, 117-126.

https://doi.org/10.11005/jbm.2014.21.2.117

[28] Jolly, S.J., Hedge, C. and Shetty, N.S. (2015) Assessment of Maxillary and Mandibular Bone Density in Controlled Type II Diabetes: A Computed Tompgraphy Study. Journal of Oral Implantology, 12, 400-405. https://doi.org/10.1563/AAID-JOI-D-12-00248

[29] Bidez, M.W. and Mish, C.E. (2021) Clinical Biomechanics in Implant Dentistry. In: Mish, C.E., Ed., Contemporary Implant Dentistry, 4th Edition, Mosby, Elsevier, Amsterdam, 140-151.

[30] Resnik, R.R. (2021) Prosthetic Option in Implant Dentistry. In: Mish, C.E., Ed., Contemporary Implant Dentistry, 4th Edition, Mosby, Elsevier, Amsterdam, 436-449.

[31] Bullis, G. (2021) Functional Basis for Dental Implant Design. In: Mish, C.E., Ed., Contemporary Implant Dentistry, 4th Edition, Mosby, Elsevier, Amsterdam, 48-68.

[32] Sanfilippo, F. and Bianchi, A.E. (2003) Osteoporosis: The Effect on Maxillary Bone Resorption and Therapeutic Possibilities by the Means of Implant Prosthesis-A Literature Review and Clinical Considerations. International Symposium on Peri- 
odontics \& Restorative Dentistry, 23, 447-57.

[33] Al-Attas, M.A., Koppolu, P., Alannazi, S.A., Parameaswari, P.J., Swapana, L.A., Almoallim, H. and Krishnan, P. (2020) Radiographic Evaluation of Bone Density in Dentulous and Edentulous Patients. Nigerian Journal of Clinical Practice, 23, 258-256.

[34] Hart, N.H., Nimphius, S., Rantalainen, T., Ireland, A., Siafarikas, A. and Newton, R.U. (2017) Mechanical Basis of Bone Strength: Influence of Bone Material, Bone Structure and Muscle Action. Journal of Musculoskeletal and Neuronal Interactions, 17, 114-139.

[35] Melo, J.B., Ibacache, V.T., Kurzik, K. and Buvinic, S. (2019) Mandibular Bone Loss after Masticatory Muscle Intervention with Botulinum Toxin: An Approach from Basic Research to Clinical Findings. Toxins (Basel), 11, 84.

https://doi.org/10.3390/toxins11020084 